\title{
Two primary cancers: Primary squamous cell carcinoma with extensive ichthyosis uteri and cervical endometrioid carcinoma: A case report
}

\author{
YOSHIKA AKIZAWA ${ }^{1}$, TOMOKO YAMAMOTO ${ }^{2,3}$, TOSHIYUKI KANNO ${ }^{1}$, YU HORIBE ${ }^{1}$, \\ KENSUKE ODAIRA $^{1}$, YUKI ABE ${ }^{1}$, YOJI NAGASHIMA ${ }^{2}$ and TSUTOMU TABATA ${ }^{1}$ \\ Departments of ${ }^{1}$ Obstetrics and Gynecology, ${ }^{2}$ Surgical Pathology and ${ }^{3}$ Pathology and Neuroscience, \\ Tokyo Women's Medical University, Tokyo 162-8666, Japan
}

Received October 20, 2019; Accepted March 23, 2020

DOI: $10.3892 / \mathrm{mco} .2020 .2113$

\begin{abstract}
Squamous cell carcinoma of the endometrium is extremely rare, accounting for approximately $1 \%$ of uterine body malignancies. The present report describes a case of squamous cell carcinoma of the uterine body arising from ichthyosis due to persistent pyometra. A 68-year-old Japanese woman, gravida 1 para 1, was referred to the Gynecological Department of Tokyo Women's Medical University, due to watery brown vaginal discharge which had persisted for 10 days. Pelvic magnetic resonance (MRI) imaging revealed a tumorous lesion occupying the cervical uteri, measuring $3 \mathrm{~cm}$ in diameter, and pyometra. The endometrial biopsy specimen obtained after drainage of the purulent fluid in the uterus was insufficient for obtaining a definitive pathological diagnosis. Under a clinical diagnosis of cervical tumor and pyometra, total transabdominal hysterectomy with bilateral salpingo-oophorectomy was performed. Histopathologically, two primary cancers were diagnosed, i.e., cervical endometrioid carcinoma and squamous cell carcinoma of the endometrium. The patient was treated with additional chemotherapy with carboplatin (area under the curve, 6) and paclitaxel $\left(175 \mathrm{mg} / \mathrm{m}^{2}\right.$ ). The patient has remained alive, without recurrence, for 1 year to date. In this case, preexisting cervical endometrioid carcinoma caused stenosis of the uterine orifice and also resulted in pyometra. The uterine body squamous cell carcinoma appeared to have been caused by persistent inflammatory stimuli to the endometrium. One must be cautious regarding cancer in elderly postmenopausal females presenting with pyometra. The findings in this case report suggest that chronic inflammation of
\end{abstract}

Correspondence to: Dr Yoshika Akizawa, Department of Obstetrics and Gynecology, Tokyo Women's Medical University, 8-1 Kawada-cho, Shinjuku, Tokyo 162-8666, Japan

E-mail: akizawa.yoshika@twmu.ac.jp

Key words: two primary cancers, primary squamous cell carcinoma of the endometrium, endometrioid carcinoma, ichthyosis uteri, pyometra, elderly postmenopausal female the endometrium may be associated with primary squamous cell carcinoma of the endometrium.

\section{Introduction}

Squamous cell carcinoma of the endometrium is rare. We report a 68-year-old woman who presented with brown discharge and was found to have concomitant squamous cell carcinoma of the endometrium and cervical endometrioid carcinoma. Pelvic ultrasonography demonstrated $300 \mathrm{ml}$ of purulent material, i.e., pyometra. Pelvic magnetic resonance imaging (MRI) also showed a tumorous lesion occupying the cervical uteri, measuring $3 \mathrm{~cm}$ in diameter, as well as confirming the pyometra. Total abdominal hysterectomy with bilateral salpingo-oophorectomy was performed, and the clinical diagnosis was cervical tumor with concomitant pyometra. An existing primary cancer involving two organs in a single patient is a rarity in the medical literature. Herein, we report a rare case with two primary cancers, of different histological types, one involving the cervical uteri and the other the uterine body. Chronic and widespread inflammation of the endometrium associated with overt ichthyosis may predispose to the development of primary squamous cell carcinoma of the endometrium (PSCCE). PSCCE should be considered in the differential diagnosis when evaluating elderly postmenopausal women presenting with pyometra.

\section{Case report}

A 68-year-old Japanese woman, gravida 1 para 1, was admitted to our department with a chief complaint of watery brown vaginal discharge which had persisted for 10 days. She had been diagnosed with rheumatoid arthritis 23 years earlier. She had experienced menopause at the age of 50. Pelvic ultrasound showed a total of $300 \mathrm{ml}$ of fluid, and the pyometra was drained from the uterus. Pelvic MRI showed a tumor, measuring $3 \mathrm{~cm}$ in diameter, at the bottom of the endometrium and massive fluid accumulation within the irregular endometrium in the uterus (Fig. 1). After drainage of the fluid, an endometrial biopsy was performed, but the specimen obtained was not sufficient for diagnosis. Tumor of the cervical uteri and pyometra were the 

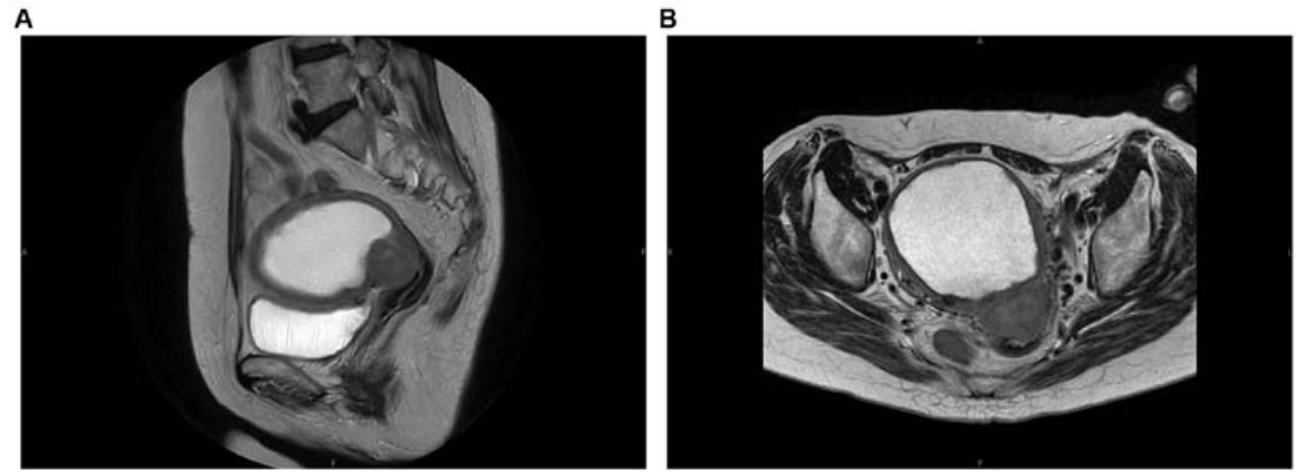

Figure 1. MRI of the pelvis. (A) Sagittal and (B) axial MRI T2-weighted images of pyometra and tumor of cervical uteri. MRI, magnetic resonance imaging.

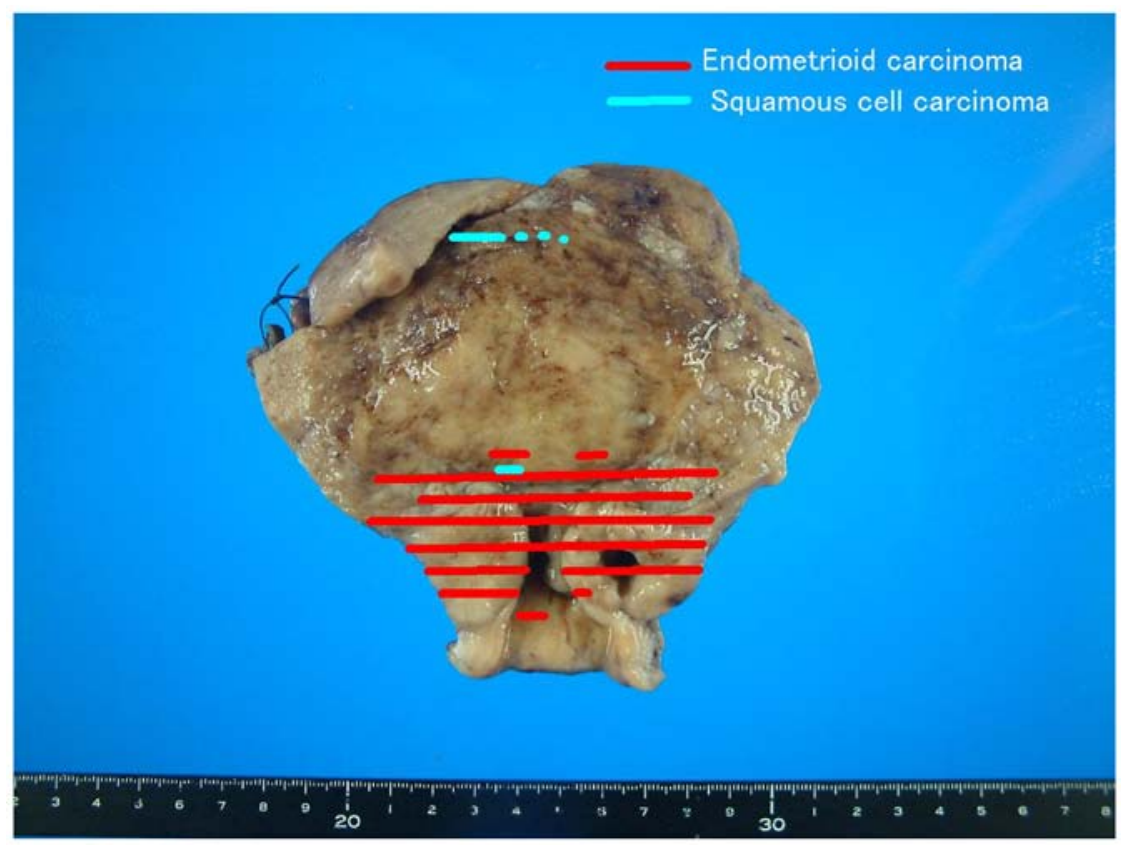

Figure 2. Gross features. A white tumor is present in the uterine cervix. Endometrioid carcinoma is indicated by the red line, squamous cell carcinoma by the blue line.

clinical diagnoses; total abdominal hysterectomy with bilateral salpingo-oophorectomy was thus performed. The patient was given chemotherapy with carboplatin (area under the curve, 6) and paclitaxel $\left(175 \mathrm{mg} / \mathrm{m}^{2}\right)$. She has remained well, without evidence of disease, for 1 year to date since the surgery. Gross findings: The resected uterus and bilateral adnexa measured $125 \times 125 \mathrm{~mm}$ in size. Macroscopically, the uterine body was markedly enlarged. The endometrial cavity was dilated, due to being filled with foul-smelling mossy debris and pus (Fig. 2). There was a whitish mass measuring $30 \times 30 \times 23 \mathrm{~mm}$ in the uterine cervix. Histologically, the cervical tumor was endometrioid carcinoma, composed of irregular-shaped neoplastic glands. The tumor tissue invaded the myometrium (Fig. 3). We added immunostaining investigation, but detected no lymphovascular involvement. Most of the endometrium had shed the epithelial lining and was covered with granulation tissue. The residual epithelia had been replaced by ichthyosis uteri which was accompanied by squamous epithelium. There were two foci of squamous cell carcinoma, one of which was close to the endometrioid carcinoma, but the upper endometrium showed no connection with the squamous epithelium of the cervix (Figs. 4 and 5). All of the tumors were negative for $\mathrm{p} 16^{\mathrm{INK} 4 \mathrm{a}}$, indicating that a contribution of the human papilloma virus to carcinogenesis was unlikely.

\section{Discussion}

Our present patient was an elderly postmenopausal woman, who had initially developed cervical endometrioid carcinoma. In this case, the cervical cancer had resulted in stenosis of the uterine orifice. Subsequently, persistent endometrial inflammatory changes with pyometra produced extensive ichthyosis uteri. Notably, this patient developed squamous cell carcinoma in the endometrium with two foci. Ichthyosis uteri is characterized by replacement of the entire endometrial surface by stratified squamous epithelium $(1,2)$. PSCCE can arise from squamous metaplasia of the endometrium (3). Many factors predisposing to the development of PSCCE have been suggested, including pyometra, radiation, and abnormal estrogen levels $(1,2,4,5)$. The pyometra in this patient had been 
A

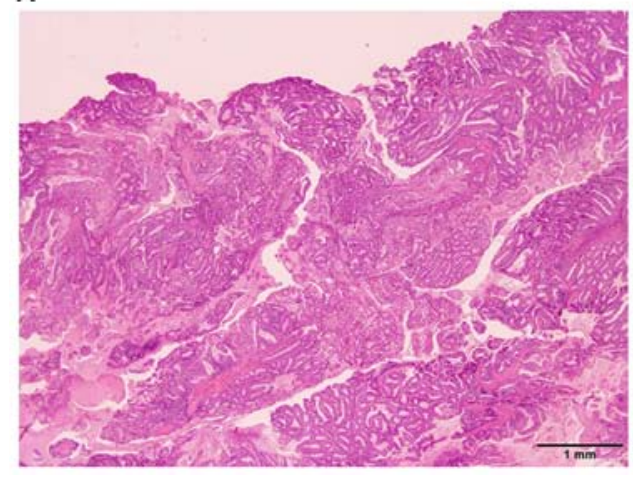

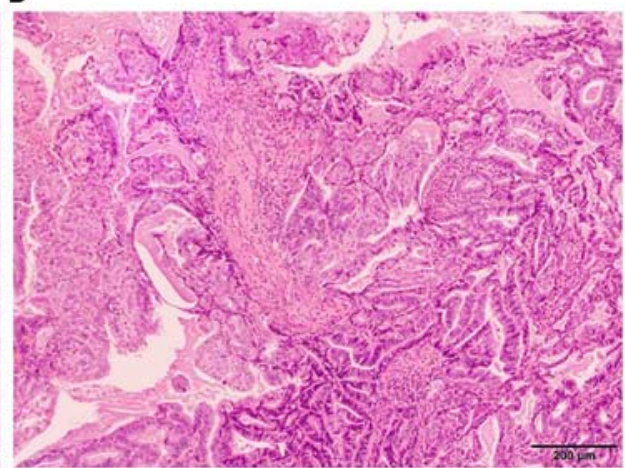

Figure 3. Histologically, the cervical tumor was endometrioid carcinoma. (A) Low magnification and (B) high magnification.

A

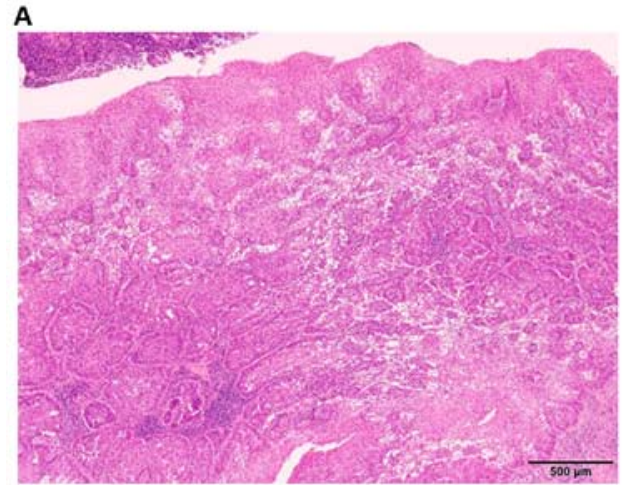

B

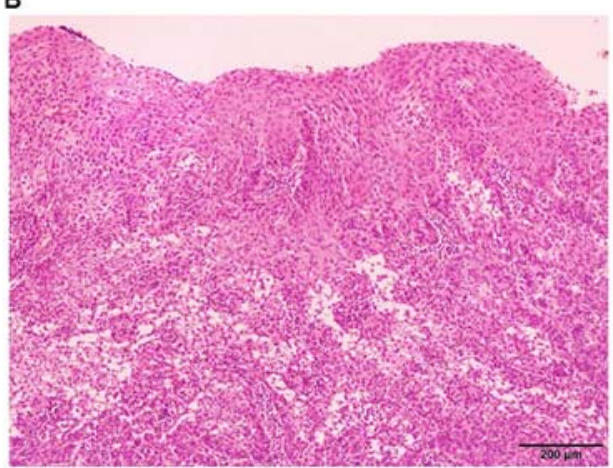

Figure 4. There were two foci of squamous cell carcinoma in the uterine body. The squamous cell carcinoma of the upper endometrium was not connected with the squamous epithelium of the cervix. (A) Low magnification and (B) high magnification.

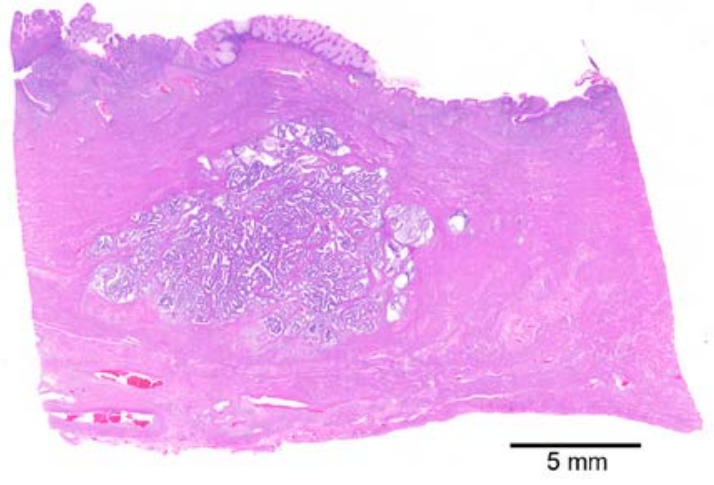

Figure 5. Squamous cell carcinoma was observed to be located with stromal invasion.

caused by neoplastic obstruction of the uterine orifice and persistent infection. However, the mechanisms of squamous metaplasia and malignant transformation remain unknown. No more than $50 \%$ of PSCCE cases can be definitively diagnosed prior to the surgery (5). In our present case, it was not possible to establish the diagnosis of PSCCE prior to the hysterectomy being performed. Although an endometrial biopsy should have been performed to obtain a definitive diagnosis of endometrioid cancer, this was difficult due to the cervical stenosis and pyometra. When pyometra and PSCCE are found in elderly postmenopausal women, potentially causative factors such as chronic and persistent inflammation of the endometrium leading to extensive ichthyosis uteri should be considered $(1,2)$. Hysterectomy is required, given the possibility of malignancy. PSCCE is a rare disease. Squamous cell carcinomas found in the endometrium are mostly of cervical uteri origin. Though endometrioid squamous cell carcinoma is not included in the WHO classification of tumors of Female Reproductive Organs (6), there are several reports describing endometrioid squamous differentiation and PSCCE $(1,2,7,8)$. PSCCE can be differentiated from endometrial squamous cell carcinoma involvement based on the pathological criteria proposed by Fluhmann: i) no evidence of a coexisting endometrial adenocarcinoma or primary cervical squamous cell carcinoma; ii) no connection between the endometrial tumor and squamous epithelium of the cervix; iii) no connection between any in situ carcinoma of cervix and endometrial neoplasm (9). Our present case fulfilled the criteria proposed by Fluhmann. Thus, we diagnosed the patient as having two primary cancers, i.e., endometrioid carcinoma of the cervix and PSCCE. Moreover, this patient had been taking methotrexate for several years as treatment for rheumatoid arthritis. The resulting immunocompromised state might have exacerbated the persistent inflammation, possibly contributing to the development of PSCCE (10).

In conclusion, the possibility of PSCCE should be considered in elderly postmenopausal women presenting with long-standing pyometra. Chronic and extensive inflammation of the endometrium associated with overt ichthyosis uteri may predispose affected individuals to the development of PSCCE. 


\section{Acknowledgements}

Not applicable.

\section{Funding}

This study was supported in part by JSPS KAKENHI (grant no. $17 \mathrm{~K} 11162$ to $\mathrm{YN}$ ).

\section{Availability of data and materials}

All data generated or analyzed during this study are included in this published article.

\section{Authors' contributions}

YAk, TY, YN and TT collaborated in the conception and design of the study. YAk and YN wrote the manuscript. TY, TK, YH, $\mathrm{KO}, \mathrm{YAb}$ and $\mathrm{YN}$ analyzed the data and reviewed the manuscript. All authors were involved in writing the manuscript. All authors read and approved the final manuscript.

\section{Ethics approval and consent to participate}

Not applicable.

\section{Patient consent for publication}

Written informed consent for publication of clinical details was obtained from the patient.

\section{Competing interests}

The authors declare that they have no competing interests.

\section{References}

1. Jain M, Kashyap A and Biswas R: Primary endometrial squamous cell carcinoma in-situ with extensive ichthyosis uteri A rare case report. J Clin Diagn Res 11: ED13-ED14, 2017.
2. Takeuchi K, Tsujino T, Yabuta M and Kitazawa S: A case of primary squamous cell carcinoma of the endometrium associated with extensive 'ichthyosis uteri'. Eur J Gynaecol Oncol 33: 552-554, 2012.

3. Lee SJ and Choi HJ: Primary endometrial squamous cell carcinoma: A case report and review of relevant literature on Korean women. Korean J Pathol 46: 395-398, 2012.

4. Baggish MS and Woodruff JD: The occurrence of squamous epithelium in the endometrium. Obstet Gynecol Surv 22: 69-115, 1967.

5. Goodman A, Zukerberg LR, Rice LW, Fuller AF, Young RH and Scully RE: Squamous cell carcinoma of the endometrium: A report of eight cases and a review of the literature. Gynecol Oncol 61: 54-60, 1996.

6. Kurman RJ, Carcangiu ML, Herrington CS, Young RH; IARC WHO Classification of Tumours of Female Reproductive Organs. 4rth edition. In: WHO Classification of Tumours, vol. 6. IARC, Lyon, France, 2014.

7. Farhane FZ, Alami Z, Bouhafa T, Elmazghi A and Hassouni K Primary squamous cell carcinoma of endometrium: Case report and literature review. Pan Afr Med J 30: 208, 2018.

8. Terada T and Tateoka K: Primary pure squamous cell carcinoma of the endometrium: A case report. Int J Clin Exp Pathol 6: 990-993, 2013.

9. Fluhmann CF: The histogenesis of squamous cell metaplasia of the cervix and endometrium. Surg Gynecol Obstet 97: 45-58, 1953.

10. Lim XR, Xiang W, Tan JWL, Koh LW, Lian TY, Leong KP and Koh ET; TTSH Rheumatoid Arthritis Study Group: Incidence and patterns of malignancies in a multi-ethnic cohort of rheumatoid arthritis patients. Int J Rheum Dis 22: 1679-1685, 2019.

This work is licensed under a Creative Commons Attribution-NonCommercial-NoDerivatives 4.0 International (CC BY-NC-ND 4.0) License. 